\title{
Correction: Repurposing dextromethorphan and metformin for treating nicotine-induced cancer by directly targeting CHRNA7 to inhibit JAK2/STAT3/SOX2 signaling
}

Lu Wang, Liang Du, Xiao Xiong, Yusheng Lin, Jianlin Zhu, Zhimeng Yao, Shuhong Wang, Yi Guo, Yuping Chen, Kyla Geary, Yunlong Pan, Fuyou Zhou, Shegan Gao, Dianzheng Zhang, Sai-Ching Jim Yeung (D) and Hao Zhang (iD)

(c) The Author(s) 2021

Oncogene (2021) 40:5356; https://doi.org/10.1038/s41388-021-01936-w

Correction to: Oncogene https://doi.org/10.1038/s41388-02101682-z, published online 18 February 2021

Only after the article was published online did the authors notice the misspelling of the second author's name. It should be "Liang $\mathrm{Du}^{\prime}$ " instead of "Du Liang". The authors sincerely apologize for any inconvenience this might have caused.

The original article has been corrected. cc (i) Open Access This article is licensed under a Creative Commons adaptation, distribution and reproduction in any medium or format, as long as you give appropriate credit to the original author(s) and the source, provide a link to the Creative Commons license, and indicate if changes were made. The images or other third party material in this article are included in the article's Creative Commons license, unless indicated otherwise in a credit line to the material. If material is not included in the article's Creative Commons license and your intended use is not permitted by statutory regulation or exceeds the permitted use, you will need to obtain permission directly from the copyright holder. To view a copy of this license, visit http://creativecommons. org/licenses/by/4.0/.

(c) The Author(s) 2021 